\title{
Comunicación
}

\section{Determinación de residuos de tetraciclina en carne de cerdos beneficiados en dos camales de Lima (2018)}

\author{
Determination of tetracycline residues in pork meat from two \\ slaughterhouses in Lima (2018)
}

\author{
Jehason Huanilo Tarazona ${ }^{1}$, Siever Morales-Cauti ${ }^{1,2}$
}

\section{Resumen}

\begin{abstract}
El objetivo del estudio fue determinar la presencia de residuos de tetraciclina en la carne de cerdo en dos camales de Lima durante 2018. Se procesaron $25 \mathrm{~g}$ de carne del cuello de 402 cerdos beneficiados. Las muestras fueron obtenidas en la etapa de oreo y se evaluó mediante la técnica microbiológica de difusión enfrentando las muestras a la cepa de Bacillus subtilis ATCC 6633. Posteriormente se confirmó la presencia de tetraciclina mediante la técnica de ELISA MaxSignal Tetracycline Test Kit. No se encontraron muestras positivas a la prueba microbiológica de difusión. E1 7.32\% (6/82) resultó positiva a una concentración de tetraciclina entre 1587 y $5811 \mathrm{ppb}$. Ninguna de las muestras positivas superó los límites permitidos en el país.
\end{abstract}

Palabras clave: límite máximo residual, tetraciclina, ELISA, prueba microbiológica

\section{Abstract}

The aim of this study was to determine the presence of tetracycline residues in pork in two herds of Lima during 2018. In total, $25 \mathrm{~g}$ of meat from the necks of 402 slaughtered pigs were processed. The samples were obtained in the cooling stage and

\footnotetext{
${ }^{1}$ Carrera de Medicina Veterinaria y Zootecnia, Universidad Científica del Sur, Lima, Perú

2E-mail: sieverm@hotmail.com
}

Recibido: 17 de marzo de 201

Aceptado para publicación: 20 de octubre de 2021

Publicado: 22 de diciembre de 2021

CLos autores. Este artículo es publicado por la Rev Inv Vet Perú de la Facultad de Medicina Veterinaria, Universidad Nacional Mayor de San Marcos. Este es un artículo de acceso abierto, distribuido bajo los términos de la licencia Creative Commons Atribución 4.0 Internacional (CC BY 4.0) [https:// creativecommons.org/licenses/by/4.0/deed.es] que permite el uso, distribución y reproducción en cualquier medio, siempre que la obra original sea debidamente citada de su fuente original 
evaluated using the microbiological diffusion technique, confronting the samples against the Bacillus subtilis strain ATCC 6633. Subsequently, the presence of tetracycline was confirmed by the ELISA MaxSignal Tetracycline Test Kit. None of the samples were positive to the microbiological diffusion test. However, $7.32 \%(6 / 82)$ were positive at a tetracycline concentration between 1587 and $5811 \mathrm{ppb}$. None of the positive samples exceeded the limits allowed in the country.

Key words: maximum residual limit, tetracycline, ELISA, microbiological test

\section{INTRODUCCIÓN}

La carne de cerdo es una de las más consumidas a nivel mundial, por su calidad magra y poca infiltración grasa. El consumo per cápita en el Perú se ha ido incrementado año tras año (Asociación Peruana de Porcicultores, 2021), lo cual ha traído consigo que se haya incrementado la producción porcina, tanto tecnificada y semitecnificada como a nivel de traspatio (MINAGRI, 2017a). Según el Sistema Integrado de Estadísticas Agrarias (SIEA), la población porcina a nivel nacional fue de 3187254 animales en 2016 (SIEA, 2016). Las regiones con mayor participación en la producción de cerdos son Lima metropolitana, Lima provincia, La Libertad, Arequipa, Ica y Huánuco (MINAGRI, 2016, 2017b).

Ante el incremento de la producción porcina crece el riesgo de que se presenten brotes infecciosos, tanto de origen viral como bacterianos, especialmente en la etapa de recría y engorda, debido a que se manejan grupos relativamente grandes con mayor posibilidad de contacto entre animales. Ante eso, se observa un incremento del uso de antibióticos, muchas veces de forma inadecuada(Limaet al., 2020), pues no solo se les utiliza con fines terapéuticos sino también con fines profilácticos así como como promotores de crecimientos (Miranda, 2007; Quintana et al., 2009). La aplicación de la tetraciclina en animales de producción destinados al consumo humano se da por su am- plia capacidad bacteriostática contra bacterias grampositivas y gramnegativas, además de que puede ser incluida dentro de la formulación del alimento o administrarse vía intramuscular (Chopra y Roberts, 2001).

La aparición de bacterias con genes de resistencia a antibióticos se ha convertido en un problema a nivel mundial. Para el caso de la tetraciclina se reconocen 39 genes de resistencia, siendo el primer mecanismo de resistencia el eflujo activo, el segundo es la protección ribosomal de la bacteria, el tercero es la inactivación enzimática y el ultimo mecanismo, aún desconocido, está ligado a un gen de resistencia, a diferencia de los demás mecanismos donde participan varios genes (Chopra y Roberts, 2001).

Se dispone de varios reportes sobre genes de resistencia bacteriana a tetraciclina en animales de producción como porcinos y bovinos, entre ellos el de Yamamoto et al. (2001) en la bacteria Erysipelothrix rhusiopathiae, causante de la erisipela porcina, el de Miranda et al. (2003) en bacterias del género Pasteurella y el de Jara (2007), quien reportó la presencia de estos genes de resistencia en el Hospital Veterinario de la Facultad de Ciencias Veterinarias de Chile

La presencia de residuos de medicamentos veterinarios como la tetraciclina en carne es considerada por el Codex Alimentarius y diversos organismos internacionales como un riesgo para la salud humana (Iwu et 
al., 2020). Por esta razón se han establecido límites máximos permisibles de residuos para este antibiótico en animales de producción y en órganos dianas como el músculo, hígado y riñón, así como en la leche (CEE, 1990). Dentro de la normativa peruana se ha creado la Ley de Inocuidad de los Alimentos (Ley N. ${ }^{\circ} 1062$ ) donde se menciona que los límites máximos de residuos de medicamentos veterinarios no contemplados en tal norma sanitaria (Ley $\mathrm{N}^{\circ} 1062$ ) se regirán por lo dispuesto en el Codex Alimentarius, que para el caso de la carne de cerdo tendría un límite máximo residual de $200 \mathrm{ppb}$ (Codex Alimentarius, 2018; Resolución Ministerial 739-2012MINSA).

Debido a que la estabilidad química de la tetraciclina se afecta fácilmente por factores tales como la temperatura, los tratamientos calóricos relativamente cortos como la cocción de la carne desencadena la ruptura térmica de este antibiótico formando metabolitos tóxicos como la anhidrotetraciclina, 4-epitetraciclina, 4epi-anhidrotetraciclina. El consumo de estos metabolitos en la dieta a largo plazo está relacionado con el síndrome de Fanconi (Gratacós-Cubarsí et al., 2007).

Por todo lo expuesto, el objetivo del estudio fue determinar cualitativa y cuantitativamente la presencia de tetraciclina en la carne de cerdos beneficiados en dos camales de Lima, mediante la técnica modificada de sensibilidad por difusión en agar y la prueba comercial ELISA MaxSignal Tetracycline Test Kit.

\section{Materiales y MéTOdos}

La toma de muestra se llevó a cabo en dos camales de la ciudad de Lima y el procesamiento de las muestras en el Laboratorio de Microbiología de la Universidad Científica del Sur ubicada en Lima, Perú, entre enero y marzo de 2018.
La población en estudio fueron las carcasas de cerdo doméstico (Sus scrofa domesticus) beneficiados. El tamaño de la muestra $(\mathrm{n}=385)$ se determinó mediante la fórmula para proporciones de poblaciones no finitas, ya que la población total de animales beneficiados no es constante, y tiende a variar según la época de año. No obstante, dadas las facilidades prestadas por los camales el número total de muestras se amplió a 402, las cuales se seleccionaron aleatoriamente.

Las muestras de carne fueron tomadas de la zona del cuello ( $25 \mathrm{~g})$ en el área de oreo. Las muestras fueron guardadas en bolsas de polietileno herméticas de primer uso y refrigeradas en un cooler a $4{ }^{\circ} \mathrm{C}$ para su traslado al laboratorio en un periodo no mayor a $3 \mathrm{~h}$. Las muestras luego de su arribo al laboratorio fueron procesadas dentro de las $24 \mathrm{~h}$.

Se debridó el tejido graso y vasos sanguíneos anexos al paquete muscular previo al análisis microbiológico. Se utilizó la técnica modificada de sensibilidad por difusión en agar (Monroy et al., 2015) y la prueba comercial ELISA MaxSignal Tetracycline Test Kit según las indicaciones del fabricante con una capacidad de detección de tetraciclina de 0.05 hasta $200 \mathrm{ppb}$.

Se cultivó la cepa de Bacillus subtilis ATCC 6633, caracterizada por su alta susceptibilidad bacteriana, se reactivó la cepa en BHI (Brain Heart Infusion) y se tomó una alícuota de $100 \mu \mathrm{l}$ del caldo y se suspendió en una solución estéril de caldo de tripticasa de soya, incubándose por 24 horas a $37^{\circ} \mathrm{C}$, esperando ver un grado de turbidez de 0.5 en la escala de McFarland. Luego se procedió al sembrado en agar Mueller Hinton. Para esto, utilizando un sacabocado se colocaron cinco trozos de músculo de cerdo por placa y como control positivo se colocó un disco sensibilidad de tetraciclina $(30 \mu \mathrm{g})$. Las placas se incubaron por 24 horas a $37{ }^{\circ} \mathrm{C}$ y posteriormente se midió el halo de inhibición bacteriana generado por los potenciales residuos de antibióticos presentes. 
Para la cuantificación de los límites máximos residuales de tetraciclina, se tomaron 82 muestras al azar debido a la capacidad de lectura del kit. Las muestras fueron trituradas para lograr una masa homogénea. Se colocó $1 \mathrm{~g}$ por muestra en tubos Falcon y se añadió $3 \mathrm{ml}$ de la solución $1 \mathrm{X}$ Oxytet extraction buffer y $1 \mathrm{ml}$ de N-Hexano. Los tubos fueron agitados en un vórtex por 10 min, luego se aspiró $200 \mu 1$ de cada sobrenadante y se transfirieron a nuevos tubos Falcon. A esto se le añadió $300 \mu 1$ de la solución 1X TET simple balance buffer, para volver a agitar en el vórtex por $1 \mathrm{~min}$. Finalmente se tomaron $75 \mu \mathrm{l}$ de cada sobrenadante para el ensayo.

En la placa ELISA se añadió en duplicado $75 \mu \mathrm{l}$ de cada estándar de tetraciclina de diferentes concentraciones $(0.05,0.15,0.4$, $0.8,1.6 \mathrm{ppb}$ ) y un control negativo; así como $75 \mu l$ de cada sobrenadante obtenido a partir de las muestras a ser evaluadas. Se siguieron las recomendaciones del protocolo descrito en el kit comercial ELISA MaxSignal Tetracycline Test. La lectura se hizo en el lector de placas BioTek ELx808 a $450 \mathrm{~nm}$ con una longitud de onda de $450 \mathrm{~nm}$.

\section{Resultados}

Todas las muestras resultaron negativas a la presencia de residuos de antibacterianos (0/402), mientras que $7.32 \%(6 / 82)$ de las muestras elegidas al azar para su evaluación por la técnica de ELISA resultaron positivas a la presencia de tetraciclina, con un rango de 1.587 a $5.811 \mathrm{ppb}$.

\section{Discusión}

En el presente estudio mediante el uso de la técnica modificada de sensibilidad por difusión en agar descrita por Monroy et al. (2015), se reporta $0 \%(0 / 402)$ de muestras positivas a la formación de un halo de inhibición bacteriana frente a la cepa de Bacillus subtilis ATCC 6633. Este resultado coincide con lo reportado por Vélez (2013), quien usó una técnica microbiológica comercial (PremiTest ${ }^{\circledR}$ ) para la detección en carne de res y de cerdo, pudiendo estar relacionado al cumplimiento del tiempo de retiro adecuado de los medicamentos en sus animales (Lima et al., 2020). Sin embargo, existen otros reportes (Hernández et al., 2005; Medina et al., 2008; Azareño y Chiroque, 2010; Monroy et al., 2015), los cuales usaron pruebas microbiológicas como primera prueba tamiz, obteniendo resultados positivos a la presencia de antibióticos por medio de los halos de inhibición bacteriana, especialmente en vísceras (hígado y riñón).

Medina et al. (2008) justifica un mayor número de muestras positivas en vísceras respecto al músculo debido a que la mayoría de las sustancias se eliminan rápidamente del tejido muscular. Según la normativa peruana (Norma Técnica de Salud NTS N ${ }^{\circ} 120$ MINSA/DIGESA-V.01), emitida por la Dirección Nacional de Seguridad Ambiental como ente regulador de los límites máximos residuales permitidos en el país, se considera como límite máximo permisible para el consumo humano la cantidad de $200 \mu \mathrm{g} / \mathrm{kg}$ de tetraciclinas en el músculo de cerdo.

La técnica modificada de sensibilidad por difusión en agar, recomendada como prueba microbiológica tamiz, al igual que otras pruebas microbiológicas descritas por Hernández et al. (2005), Medina et al. (2008) y Azañero y Chiroque (2010), usadas como pruebas de tipo cualitativas, para evidenciar la presencia o ausencia de la inhibición al crecimiento bacteriano utilizan bacterias que son sensibles a antibióticos (e.g. Bacillus subtilis ATCC 6633). Sin embargo, esta prueba es laboriosa y toma más tiempo que una prueba ELISA, aunque tiene un costo significativamente menor (Ujueta y Araque, 2016), por lo que su utilidad como prueba tamiz no es discutida, sobre todo cuando la concentración de residuos de antibióticos presente en la carne es considerable, como para evidenciar la formación de un halo de inhibición 
bacteriana. No obstante, aspectos que pudieron haber influenciado los resultados, como presencia de algún agente antibacteriano que inhiba el crecimiento del Bacilus subtilis ATCC 6633 o alteraciones en el pH del agar (Gatica y Gesche, 2007) no son válidos para las condiciones del presente estudio.

La prueba comercial de ELISA presentó $7.32 \%(6 / 82)$ de muestras positivas a la presencia de tetraciclina, frecuencia que coincide con el estudio de Ujueta y Araque (2016), quienes encontraron la presencia de tres antibióticos en 9.7\% (15/72) para betalactámicos, $0 \%(0 / 3)$ para aminoglucósidos, y $100 \%(1 / 1)$ para sulfamidas en muestras de carne, aunque frecuencias mayores en riñón e hígado, resultado que en parte demuestra que no se respeta el tiempo de retiro de estos antibióticos antes del beneficio de los animales, influyendo de forma directa o indirecta en la resistencia antibiótica (Iwu et al., 2020; Lima et al., 2020).

El valor máximo encontrado en este estudio fue de $5.811 \mu \mathrm{g} / \mathrm{kg}$ el cual se encuentra dentro del límite permisible de $200 \mu \mathrm{g} / \mathrm{kg}$ establecido por la normativa peruana (Norma Técnica de Salud NTS N ${ }^{\circ} 120-$ MINSA/ DIGESA-V.01).

\section{Conclusiones}

- Las muestras de carne de cerdo beneficiados en dos camales de Lima resultaron negativas a la formación de un halo de inhibición bacteriana frente a la cepa de Bacillus subtilis ATCC 6633 mediante la técnica modificada de sensibilidad por difusión en agar.

- Las concentraciones de tetraciclina obtenidas mediante la técnica de ELISA no superaron los límites máximos residuales permitidos por la normativa peruana y el Codex Alimentarius.

\section{Literatura Citada}

1. Azareño G, Chiroque M. 2010. Detección y cuantificación de residuos antimicrobianos en tejido muscular de pollo en cuatro mercados de Lima Cercado. Tesis de Químico Farmacéutico. Lima: Univ. Nacional Mayor de San Marcos. 83 p.

2. [CEE] Comunidad Económica Europea. 1990. Reglamento No $2377 / 90$ del Consejo de 26 de junio de 1990 por el que se establece un procedimiento comunitario de fijación de los límites máximos de residuos de medicamentos veterinarios en los alimentos de origen animal. [Internet]. Disponible en: https:// ec.europa.eu/health//sites/health/files/ files/eudralex/vol-5/reg_1990_2377 cons 2008/reg 19902377 consol_es.pdf

3. Chopra I, Roberts M. 2001. Tetracycline antibiotics: mode of action, applications, molecular biology and epidemiology of bacterial resistance. Microbiol Mol Biol R 65: 232-260. doi: 10.1128/ MMBR.65.2.232-260.2001

4. Codex Alimentarius. 2018. Límites máximos de residuos (LMR) y recomendaciones sobre la gestión de riesgos (RGR) para residuos de medicamentos veterinarios en los alimentos. CAC/MRL 2-2018. [Internet]. Disponible en: http:// www.fao.org/fao-who-codexalimentarius/sh-proxy/en/? $1 \mathrm{nk}=$ $1 \&$ url $=$ https $\% 253 \mathrm{~A} \% 252 \mathrm{~F} \% 252 \mathrm{~F}$ workspace.fao.org\% $\% 252$ Fsites $\% 252$ F c od ex \% 252 F S t a nd ard s \% 252FCXM\%-2B2\%252FMRL2s.pdf

5. Gratacós-Cubarsí M, FernandezGarcía A, Picouet P, Valero-Pamplona A, García-Regueiro JA, Castellari M. 2007. Formation of tetracycline degradation products in chicken and pig meat under different thermal processing conditions. J Agr Food Chem 55: 46104616. doi: 10.1021/jf070115n 
6. Gatica C, Gesche E. 2007. Métodos de las 5 placas para la detección de residuos de antibacterianos en leche. Rev Cient 17: 321-328.

7. Hernández V, Pacheco C, Gonzáles D, Montelongo M, Flores R, Kühne M. Identificación de penicilina y tetraciclina en músculo y riñón de bovino y cerdo, mediante electroforesis en gel con alto voltaje. En: Avances en la Investigación Científica en el CUCBA. Guadalajara, México.

8. Iwu CD, Korsten L, Okoh AI. 2020. The incidence of antibiotic resistance within and beyond the agricultural ecosystem: A concern for public health. Microbiologyopen 9: e1035. doi: 10.1002/ mbo3.1035

9. Jara M. 2007. Tetraciclinas: un modelo de resistencia antimicrobiana. Avances Cienc Vet 22: 49-55.

10. Lima T, Domingues S, Da Silva GJ. 2020. Manure as a potential hotspot for antibiotic resistance dissemination by horizontal gene transfer events. Vet Sci 7: 110. doi: $10.3390 /$ vetsci7030110

11. Medina MS, González DG, Ramírez A. 2008. Detección de residuos antimicrobianos en tejidos comestibles y tetraciclinas en hueso de cerdo. Rev Salud Anim 30: 110-115.

12. Miranda CD, Kerhenberg C, Ulep C, Schwarz S, Roberts M. 2003. Diversity of tetracycline resistance genes in bacteria from Chilean salmon farms. Antimicrob Agents Ch 47: 883-888. doi: 10.1128/aac.47.3.883-888.2003

13. Miranda JM. 2007. Tratamientos antimicrobianos en medicina veterinaria: efectos sobre la microbiota intestinal de pollos y su repercusión en carnes de producción convencional y ecológica. Tesis Doctoral. Lugo, España: Univ. Santiago de Compostela. 232 p.
14. [MINAGRI] Ministerio de Agricultura y Riego. 2016. Boletín estadístico de producción agrícola, pecuaria y avícola - diciembre 2016. Lima: Dirección General del Seguimiento y Evaluación de Políticas.

15. [MINAGRI] Ministerio de Agricultura y Riego. 2017. Boletín estadístico de producción agrícola y ganadera - I trimestre 2017a. Lima: Dirección General del Seguimiento y Evaluación de Políticas.

16. [MINAGRI] Ministerio de Agricultura y Riego. 2017. Boletín estadístico de producción agrícola y ganadera - IV trimestre 2017b. Lima: Dirección General del Seguimiento y Evaluación de Políticas.

17. Monroy-Torres $R$, Linares-Segovia B, Ramírez-Gómez X. 2015. Desarrollo de una técnica para la detección in vitro de la presencia de antibióticos en muestras de hígado de res, cerdo y pollo. CienciaUAT 9: 68-73.

18. Quintana de GA, Medina $O$, De Nóbrega J, De Abreu L, Jaimes L. 2009. Determinación de residuos de tetraciclinas: oxitetraciclina, tetraciclina y clortetraciclina en tejido muscular de porcino mediante cromatografía líquida de alta resolución. Rev Fac Farmacia 72: 11-22.

19. Resolución Ministerial N. ${ }^{\circ} 739-2012 /$ MINSA. 2012. Norma sanitaria que establece los límites máximos de residuos de medicamentos veterinarios en alimentos de consumo humano. $42 \mathrm{p}$. [Internet]. Disponible en: https://www.gob.pe/ institucion/minsa/normas-legales/ 241571-739-2012-minsa

20. [SIEA] Sistema Integrado de Estadísticas Agrarias. 2018. Boletín estadístico de producción agrícola, pecuaria y avícola 2016. [Internet]. Disponible en: http:/ /siea.minagri.gob.pe/portal/index.php/publicaciones/datos-estadisticas/anuarios 
21. Vélez C. 2013. Determinación de antibióticos en carne vacuna y porcina, proveniente del Norte Antioqueño en la planta Frigocolanta ubicada en el Municipio de Santa Rosa de Osos. Tesis de Ingeniera de Alimentos. Caldas, Colombia: Corporación Universitaria Lasallista. $67 \mathrm{p}$.

22. Yamamoto K, Sasaki Y, Ogikubo Y, Noguchi N, Sasatsu M, Takahashi T. 2001. Identification of the tetracycline resistance gene, tet (M), in Erysipelothrix rhusiopathiae. J Vet Med 48: 293-301. doi: 10.1046/j.1439-0450.2001.00442.x

23. Ujueta S, Araque A. 2016. Detección de residuos antimicrobianos en músculo, hígado y riñón de cerdo expendidos en Bogotá, Colombia. Revista UDCA 19: 371-379. 